\title{
Establish Using FEM Method of Constitutive Model for Chip Formation in the Cutting Process of Gray Cast Iron
}

\author{
Lihui Tu ${ }^{1,2, *}$ and Weimin Shi ${ }^{1}$ \\ 1 Modern textile equipment technology and Engineering research center of ministry of education, \\ Zhejiang SCI-TECH University, Hangzhou 310018, China; swm@zstu.edu.cn \\ 2 College of Mechanical and Energy Engineering, Ningbo Institute of Technology, Zhejiang University, \\ Ningbo 315100, China \\ * Correspondence: tulihuinit@126.com; Tel.: 86-574-8822-9217
}

Received: 21 November 2019; Accepted: 19 December 2019; Published: 23 December 2019

\begin{abstract}
The constitutive equation of mechanics, namely the stress-strain model of the material, is used to describe the mathematical expression of the mechanical properties of the material (stress-strain-intensity-time relationship). In the cutting simulation of metals, the material constitutive model needs to be established. To study the cutting mechanism of gray cast iron using the finite element method (FEM), a series of split Hopkinson press bar (SHPB) tests are carried out to achieve the stress-strain curves of gray cast iron under different strain rates and temperatures. In the cutting simulation of gray cast iron, the Johnson-Cook (JC) constitutive equation is used to reflect the mechanical behavior during the cutting process. The calculation of JC constants is analyzed deeply and obtained from the SHPB test data. One orthogonal finite element model is developed with the JC material model to reveal the cutting mechanism of gray cast iron. The chip formation, stress distribution, temperature distribution, and cutting force are investigated through the cutting simulation. At the same time, cutting experiments of gray cast iron are carried out for validating the simulation results. The results of the cutting simulation and experiments show a good agreement.
\end{abstract}

Keywords: constitutive equation; cast iron; cutting; segmented chip; finite element simulation; hopkinson bar; chip formation

\section{Introduction}

Cast iron is widely used in many industries due to its excellent properties, such as good casting performance, good vibration reduction, and good wear resistance [1,2]. Research concerning the cutting mechanism is helpful to the application of cast iron in industry. The cutting mechanism of metals is studied by considering the interaction between a workpiece and tool in the cutting process and various thermal-mechanical behaviors occurring in the cutting process, such as chip shape, cutting force, cutting temperature, residual stress, and tool wear. To investigate the cutting of cast iron, many scholars have worked to reveal the cutting mechanism of cast iron [3-8]. Yang and Li [3] investigated the formation mechanism of chips in the high-speed milling process of cast iron. Oliveira et al. [4] used the continuous and interrupted cutting with two grades of polycrystalline cubic boron nitride (PCBN) tools to analyze cutting performance during the turning process of white cast iron. Antônio et al. [5] adopted two surface milling tool systems in the high-speed milling process of gray cast iron. Martinez et al. [6] investigated the wear behavior of TiN and TiCN coated carbide tools during the face milling of pearlitic and ferritic ductile cast iron. Chen et al. [7] made an assessment of the abrasiveness of high chromium cast iron material on the wear performance of PCBN cutting tools during dry machining. Liu et al. [8] 
optimized the cutting parameters for reducing the power consumption in face milling of a cast iron alloy for environmental sustainability. All of the above studies used the experimental methods to study the cutting process of cast iron.

In recent years, the finite element method (FEM) has played a very important role in the investigation of the cutting process for metal materials. Many researchers have established finite element models to study the cutting process and these models include 2D and 3D models [9-22]. Xie et al. [9] used the finite element method to study the shear localization phenomena and chip formation in metal cutting process. Shih [10] established the orthogonal finite element model to reveal the formation of continuous chips in the cutting process of annealed low carbon steel. Wu and Zhang [11] investigated the effect of different cutting conditions on the milling of Ti6Al4V alloy by an orthogonal finite element model. Matsumura and Usui [12] established a finite element model based on the minimum cutting energy to predict the chip flow direction and milling force in the peripheral milling. Maurel-Pantel et al. [13] developed the 3D cutting model to perform the shoulder milling simulation of AISI 304L stainless steel by the software LS-Dynacopy. Ji et al. [14] simulated the helical milling hole process of Ti6Al4V alloy by a 3D finite element model with the damage initiation and evolution criterion. Mir et al. [15] presented a feasibility study of the potential application of the surface defect machining (SDM) method in the fabrication of silicon and similarly hard and brittle materials using a smooth particle hydrodynamics (SPH) simulation approach.

In the cutting simulation of metal materials, the constitutive model of materials is very critical for the production of accurate results [23-26]. The process of metal cutting is a thermal coupling process, including high strain and high temperature. Because the Johnson-Cook [JC] constitutive model [27] correlates the effect of temperature, stress, and strain rate on material properties, this model is widely employed in metal cutting simulation processes [28-30]. Daoud [28] investigated the influence of Johnson-Cook parameters on the chip morphology, cutting forces and contact length of tool-chip in simulation of Al2024-T3 alloy. Shrot and Bäker [29] used the Johnson-Cook constitutive model in cutting simulation of high-speed machining of AISI 52100. Wu and To [30] established the Johnson-Cook model of titanium alloy TC21 to analyze the adiabatic effect in the cutting process.

The Johnson-Cook constitutive model can be easily established from the experimental data achieved by the split Hopkinson press bar (SHPB) experiments with the different strain rate and temperature [31-37]. Wang et al. [31] used the SHPB test to investigate the dynamic mechanical behavior of alloy Inconel 718 under high temperature and strain rate in practical cutting process. Seo [32] investigated the influence of temperature on titanium alloy Ti6Al4V using high temperature SHPB experiment equipment. Zhong et al. [33] studied the ballistic properties and failure modes of the material based on the SHPB experiments. CJaspers and Dautzenberg [34] constructed a split Hopkinson pressure bar (SHPB) facility for obtaining the mechanical data at high temperatures and strain rate to determine the metal flow stress during cutting process.

The material constitutive model is the basis of finite element simulation of metal material cutting. The cutting process of metal materials includes high temperature, high strain rate. The constitutive experiments on metals need to be conducted over a wide range of temperature and strain rates so as to reflect accurately the thermal-mechanical behavior in cutting. In this paper, to investigate the mechanism in turning process of gray cast iron 200 using the finite element method, the JC constitutive model of gray cast iron for cutting simulation has been established by a high-temperature SHPB equipment. After establishing the JC material model, one orthogonal cutting model was presented to study the cutting process of gray cast iron using the software ABAQUS. The cutting phenomenon, including stress distribution, chip morphology, temperature distribution and cutting force have been obtained by simulation. Also, the cutting experiments of gray cast iron have been carried out to verify the results of cutting simulation. In addition, the cutting mechanism of gray cast iron has been revealed well through the research. 


\section{Experimental Setup}

In this paper, the material type is the gray cast iron 200. As one of the most commonly used cast irons, the strength, plasticity and toughness of gray cast iron are lower than other cast irons. But gray cast iron has high wear resistance, low notch sensitivity and special vibration damping. The X-ray photoelectron spectroscopy system (Kratos Analytical Ltd, Manchester, England) is adopted to analyze the chemical composition and the mass percentages of the chemical elements are listed in Table 1 . The mechanical properties of gray cast iron are listed in Table 2.

Table 1. Mass percentages of various elements of gray cast iron.

\begin{tabular}{cccccc}
\hline $\mathbf{C}$ & $\mathbf{S i}$ & $\mathbf{M n}$ & $\mathbf{P}$ & $\mathbf{S}$ & Fe \\
\hline 3.5 & 2.1 & 0.8 & 0.01 & 0.095 & Others \\
\hline
\end{tabular}

Table 2. Mechanical properties of gray cast iron.

\begin{tabular}{cc}
\hline Properties & Value \\
\hline Hardness $(\mathrm{HRC})$ & 43 \\
Density $\left(\mathrm{Kg} / \mathrm{m}^{3}\right)$ & 7135 \\
Elastic modulus $(\mathrm{GPa})$ & 126 \\
Heat conductivity $(\mathrm{W} / \mathrm{mk})$ & 39.2 \\
Specific heat $(\mathrm{J} / \mathrm{kg} \cdot \mathrm{K})$ & 480 \\
\hline
\end{tabular}

As one of the most important and reliable experimental methods, the split Hopkinson press bar is often used to study the dynamic mechanical behavior of various solid materials under high temperatures and strain rates. The schematic of the high temperature SHPB experiment is shown in Figure 1.

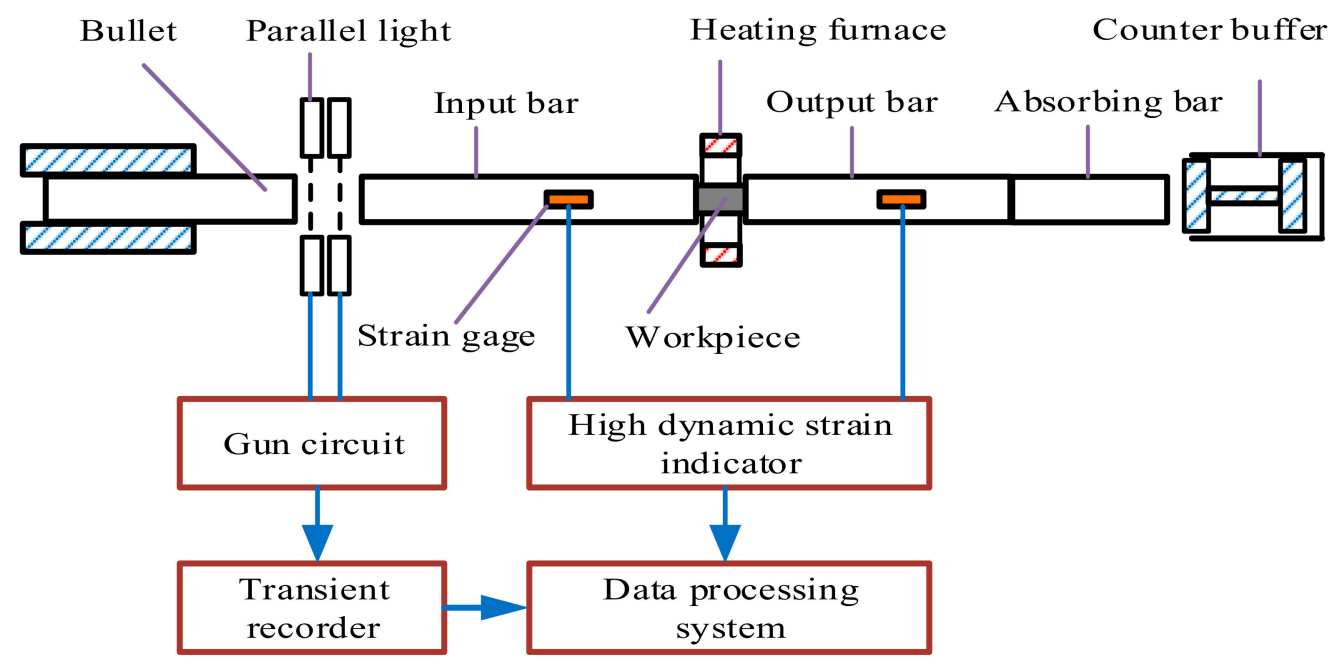

Figure 1. Schematic of high temperature SHPB experiment.

In the SHPB test process, the one-dimensional stress wave theory can be used to describe the loading process [38]. The loading process in SHPB can be described by the following equation.

$$
\begin{gathered}
\varepsilon_{S}=-\frac{2 C_{0}}{l_{S}} \int_{0}^{t} \varepsilon_{R} d t \\
\dot{\varepsilon}=\frac{d \varepsilon}{d t}=\frac{2 C_{0}}{l_{S}} \varepsilon_{R}
\end{gathered}
$$




$$
\sigma_{s}=\frac{F_{1}+F_{2}}{2 A_{S}}=\frac{1}{2} E\left(\frac{A}{A_{s}}\right)\left(\varepsilon_{I}+\varepsilon_{R}+\varepsilon_{T}\right)=E\left(\frac{A}{A_{s}}\right) \varepsilon_{T}
$$

where $\varepsilon_{I}, \varepsilon_{R}$ and $\varepsilon_{T}$ are the signal of incidence, reflectance, and transmit bar obtained by the strain gages respectively, $A_{S}$ is the area of the sample cross section, $\mathrm{L}$ is the length of the sample, while $A$ and $E$ are the area of cross section and elastic modulus of the press bar.

To obtain the dynamic mechanical properties of gray cast iron, the SHPB experiments need to be performed under a series of temperatures and strain rates. In this paper, high-speed press experiments of gray cast iron are carried out by a modified SHPB system. In this modified SHPB system, one heated system was added to the SHPB apparatus, which can avoid the problem of overheating the incident bar and improve the experimental accuracy under high temperature conditions. During the SHPB test process, all samples of gray cast iron are fixed between the incident bar and transmit bar. Then, the samples will be heated to different temperatures by the heater furnace and pressed under the different speeds. The cylindrical rod of gray cast iron will be cut into many samples by electrical discharge wire cutting. The dimension of samples and the high temperature SHPB equipment used in this research are shown in Figure 2.

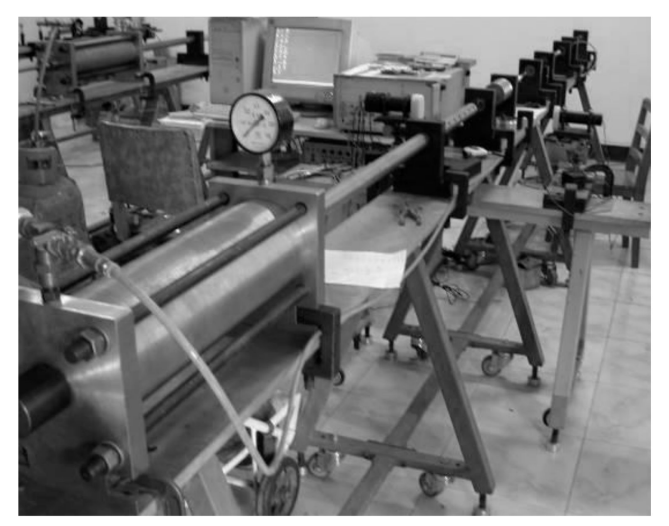

(a) Split Hopkinson press par.

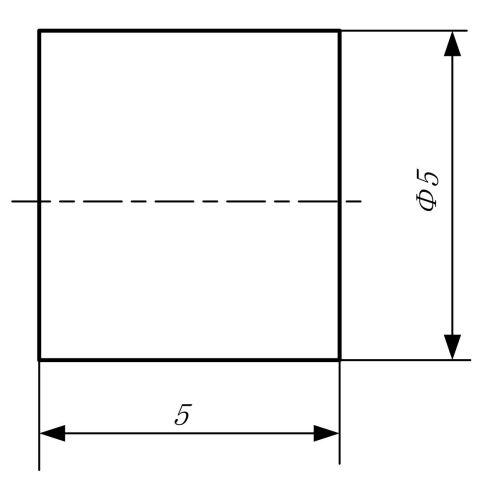

(b) Dimension of samples.

Figure 2. Equipment of the SHPB test.

The detailed parameters of SHPB experiments for gray cast iron are temperature $20^{\circ} \mathrm{C}, 200{ }^{\circ} \mathrm{C}$, $400{ }^{\circ} \mathrm{C}$ and $600{ }^{\circ} \mathrm{C}$, strain rate $500 \mathrm{~S}^{-1}, 1000 \mathrm{~S}^{-1}, 3000 \mathrm{~S}^{-1}$ and $5000 \mathrm{~S}^{-1}$. To investigate the cutting of gray cast iron a numerical control lathe machine ETC3650 (Shenyang Machine Tool Co Ltd, Shenyang, China) was used. The TiN-coated carbide inserts were used in the cutting tests. The rake angle and clearance angle of inserts are $0^{\circ}, 13^{\circ}$. The tool edge radius is $0.015 \mathrm{~mm}$. The diameter of cast iron rod is $20 \mathrm{~mm}$. The cutting experiment setup is shown in Figure 3. The cutting parameters are listed in Table 3. The cutting experiment was carried out 5 times under the same cutting parameters. A Kistler 9255B 
dynamometer (Kistler Instrumente AG Co Ltd, Winterthur, Switzerland) was adopted to acquire the cutting force.

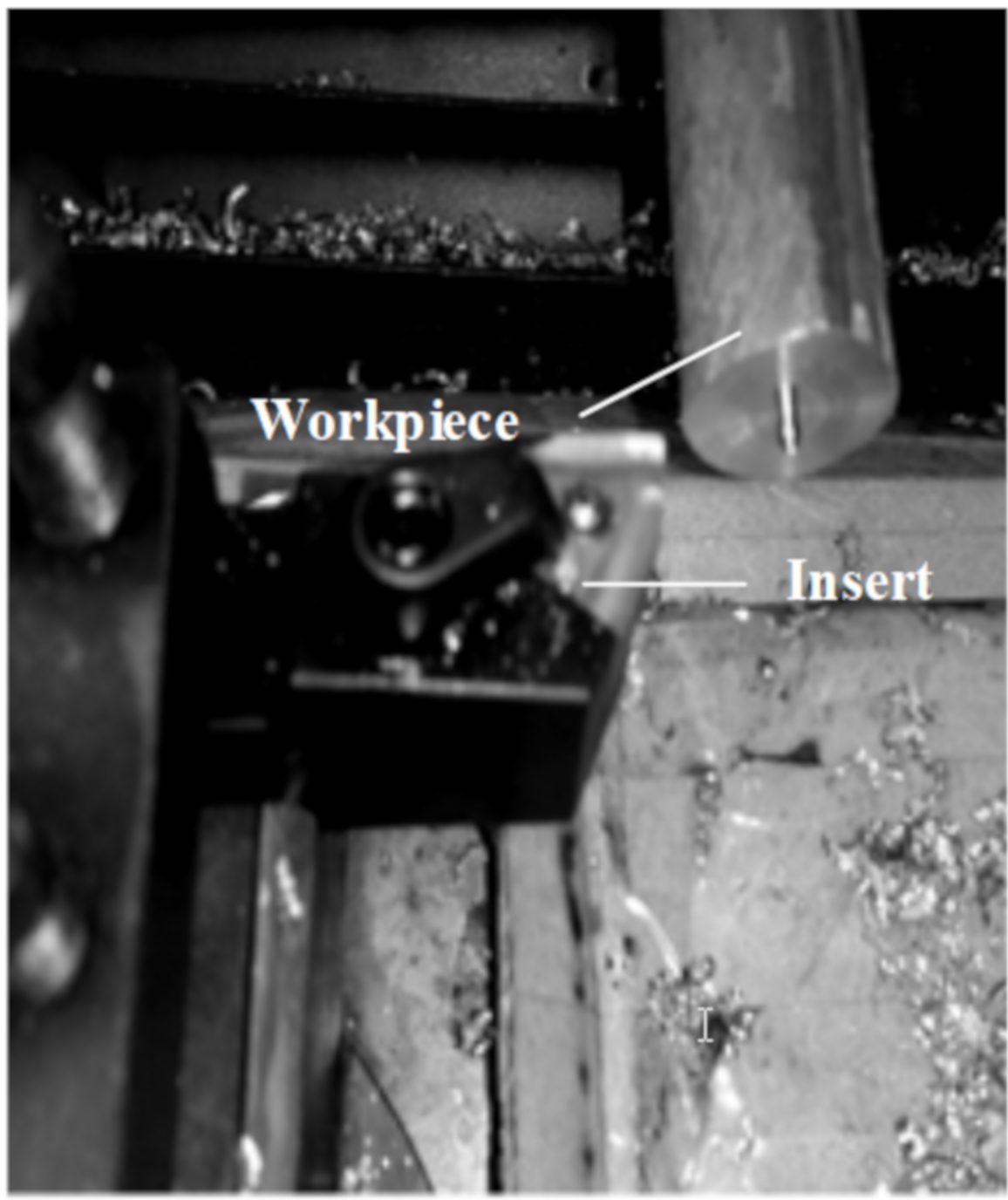

Figure 3. Turning experiments of gray cast iron.

Table 3. Cutting parameters of cast iron.

\begin{tabular}{cc}
\hline Parameters & Values \\
\hline Depth of cut $(\mathrm{mm})$ & 0.4 \\
Spindle speed $(\mathrm{r} / \mathrm{min})$ & 3000 \\
Feeding speed $(\mathrm{mm} / \mathrm{min})$ & 120 \\
Cutting speed $(\mathrm{m} / \mathrm{min})$ & 188 \\
Cutting environment & Dry cutting \\
\hline
\end{tabular}

\section{Establishment of Material Model}

The stress-strain curves obtained by the SHPB tests are shown in Figure 4. Figure 4a shows the curves with strain rate $5000 \mathrm{~S}^{-1}$ under the different temperatures, and Figure $4 \mathrm{~b}$ the curves at $600{ }^{\circ} \mathrm{C}$ under the different strain rates. Figure 4 a confirms that the strength of gray cast iron decreased with the increasing of the temperature. Figure $4 \mathrm{~b}$ shows that the strength of cast iron increased with the increasing of the temperature. So, the material cast iron is sensitive to the temperature and strain rate. In addition, these curves confirmed that cast iron is brittle material because the samples in the SHPB test have no yield phenomenon. 


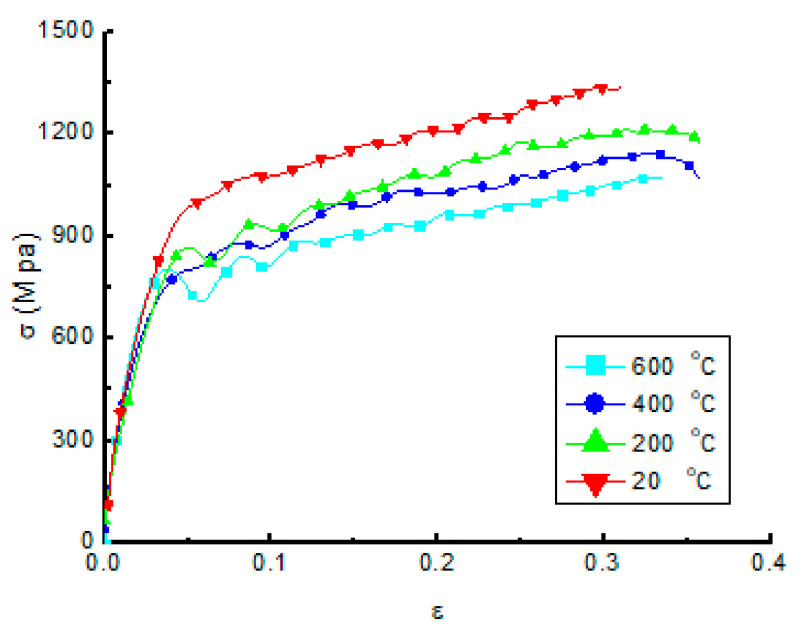

(a) $5000 \mathrm{~S}^{-1}$ under different temperature.

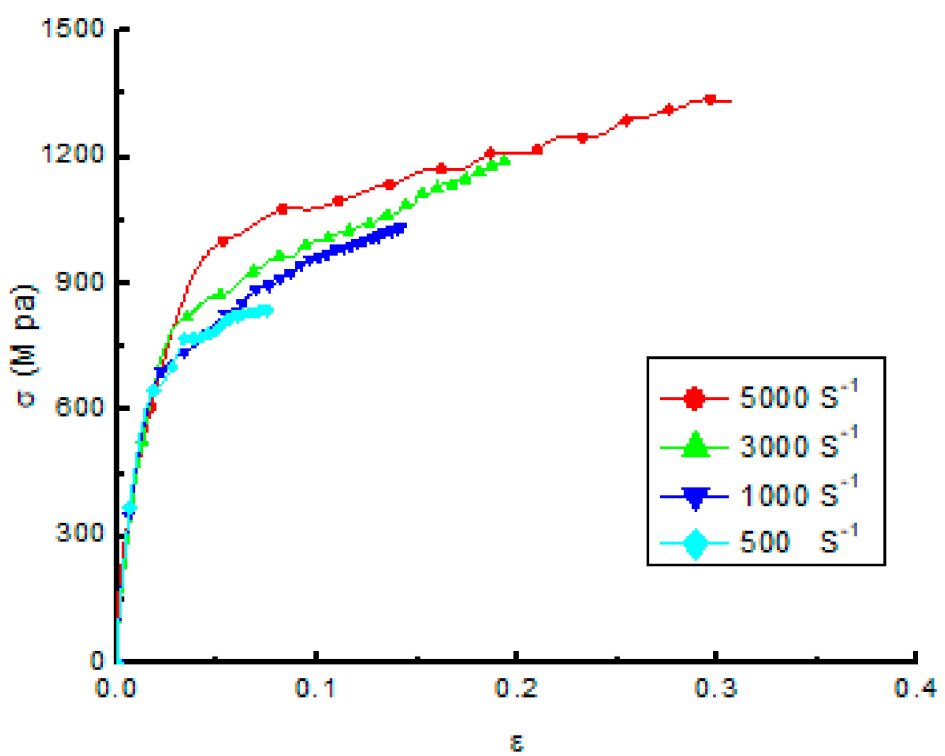

(b) $600{ }^{\circ} \mathrm{C}$ under different strain rate.

Figure 4. Stress-strain curves of gray cast iron.

The Johnson-Cook equation will be used to express the constitutive model of gray cast iron needed in the cutting simulation, which can reflect the dynamic mechanical behavior of gray cast iron under the large deformation, high strain rate, and temperature in the cutting. The Johnson-Cook equation is:

$$
\sigma=\left(A+B \varepsilon^{n}\right)\left(1+C \ln \frac{\dot{\varepsilon}}{\dot{\varepsilon}_{0}}\right)\left[1-\left(\frac{T-T_{r}}{T \cdot m-T_{r}}\right)^{m}\right]
$$

where $\varepsilon$ is the equivalent plastic strain, $\dot{\varepsilon}$ and $\dot{\varepsilon}_{0}$ are the equivalent and reference plastic strain rates. $T$, $T_{m}$ and $T_{r}$ are the temperature in cutting zone, melting and room temperature, respectively, $A, B, n, C$ and $m$ are the material constants of JC constitutive equation, representing the yield strength, strain and strain rate sensitivity, the strain hardening coefficient and the thermal softening coefficient.

The parameters of the Johnson-Cook equation for gray cast iron were calculated from the data of SHPB experiments. For the JC constants of gray cast iron, the calculation process is as follows:

$$
\sigma=A+B \gamma^{n}
$$


$A$ is equal to the initial yield stress of the material at $\dot{\varepsilon}=1 / \mathrm{s}$ and $T=T_{r}$, which can be read directly from the true stress-strain curve. $B \gamma^{n}$ is the description of the strengthening section of the stress-strain curve, and so as long as the collection point of the strengthening section is drawn on double logarithmic coordinate paper, $B$ and $n$ can be determined by the following equation:

$$
\ln \sigma=\ln B+n \ln \gamma
$$

The above equation is a line with intercept $\ln B$ and slope $\mathrm{n}$ on the double-log paper, So $n$ can be expressed:

$$
n=\frac{d(\ln \sigma)}{d(\ln \gamma)}=\frac{\Delta \ln \sigma}{\Delta \ln \gamma}
$$

This equation, $\sigma=1+C \ln \dot{\gamma}^{*}$, can be directly plotted on the semi-logarithmic coordinate paper to represent a line with intercept 1 and slope $C$, and the strain rate sensitivity coefficient $C$ can be expressed:

$$
C=\Delta \sigma / \Delta \ln \dot{\gamma}^{*}
$$

For $\sigma=1-T^{* m}$, when $T^{*}>>1, \sigma=T^{* m}$, so

$$
\ln \sigma=m \ln T^{*}
$$

This represents a line on a piece of even coordinate paper, so

$$
m=\frac{\Delta \ln \sigma}{\Delta \ln T^{*}}
$$

These parameters of gray cast iron are listed in Table 4. Figure 5 is the comparison of the stress-strain curves obtained by the experiment and Johnson-Cook equation at $600{ }^{\circ} \mathrm{C}$. The results confirm that the Johnson-Cook model agree well with the experimental data.

Table 4. Johnson-Cook parameters of gray cast iron.

\begin{tabular}{ccccc}
\hline $\boldsymbol{A}$ (Mpa) & $\boldsymbol{B}$ (Mpa) & $\boldsymbol{n}$ & $\boldsymbol{C}$ & $\boldsymbol{m}$ \\
\hline 419 & 405 & 0.2 & 0.032 & 1.2 \\
\hline
\end{tabular}

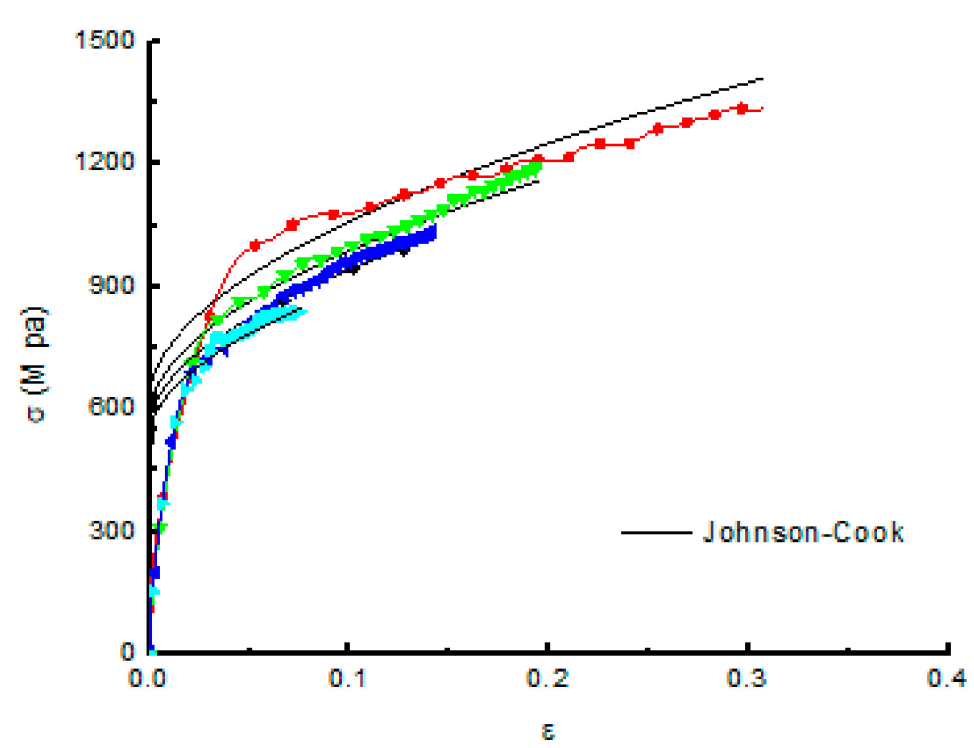

Figure 5. Comparison of Johnson-Cook model and the experiment data at $600{ }^{\circ} \mathrm{C}$. 


\section{Finite Element Models}

\subsection{Cutting Model}

One orthogonal finite element model of gray cast iron in the cutting process was developed by the finite element software ABAQUS 6.13 (Welize-villacubrai, France). The established cutting model is shown in Figure 6. To obtain the thermomechanical behavior of gray cast iron in the cutting process, the analysis step is "Dynamic Temperature-displacement, Explicit" in the cutting simulation. The dimension of workpiece is $3 \times 1.5 \mathrm{~mm}^{2}$. To improve the computational efficiency, the workpiece meshes in cutting layer have been refined and the other meshes are sparse. The number of workpiece elements is 32,800 and the element type is CPE4RT. The minimal element size is $10 \times 12 \mathrm{~nm}^{2}$. The cutting condition is set to be dry cutting. The tool has 6248 elements and the tool has a rigid body. The tool rake angle is $0^{\circ}$, the clearance angle is $13^{\circ}$, and the edge radius is $0.05 \mathrm{~mm}$. The cutting parameters in the simulation are similar to the experiments. The initial environment temperature was set to $20^{\circ} \mathrm{C}$.

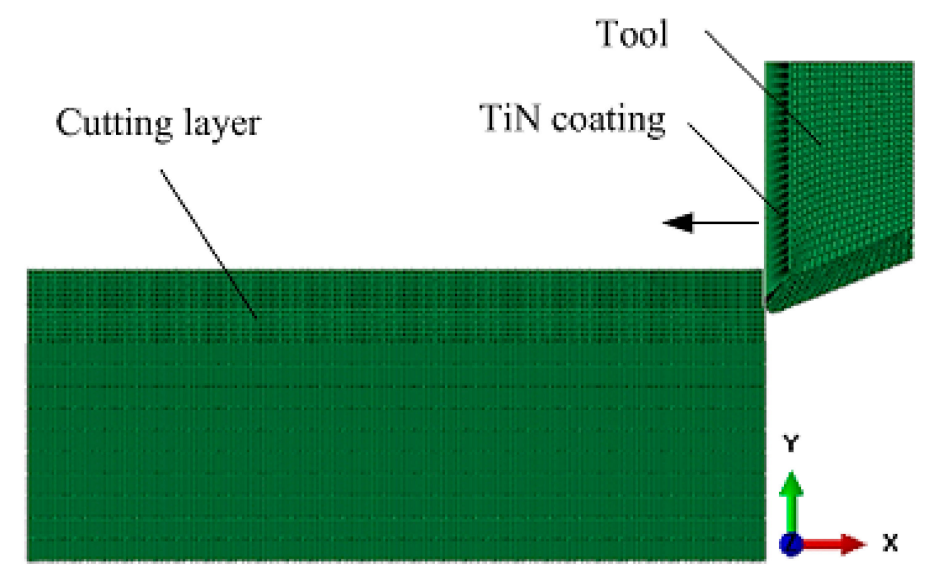

Figure 6. Orthogonal finite element cutting model of gray cast iron.

\subsection{Friction Model}

Friction between workpiece and tool has the significant effect on the cutting process. It is very important to establish the model that reflects the friction between tool and workpiece in cutting process. There exist two regions in the contact surface of the tool and workpiece, namely the sliding region and the sticking region [39]. The sliding region obeys the Coulomb friction law. The shear stress is equal to the critical frictional stress in sticking region. The frictional schematic of the contact surface between the chip and tool is shown in Figure 7. The frictional coefficient between the tool and chip is set to 0.25 in the cutting simulation of gray cast iron.

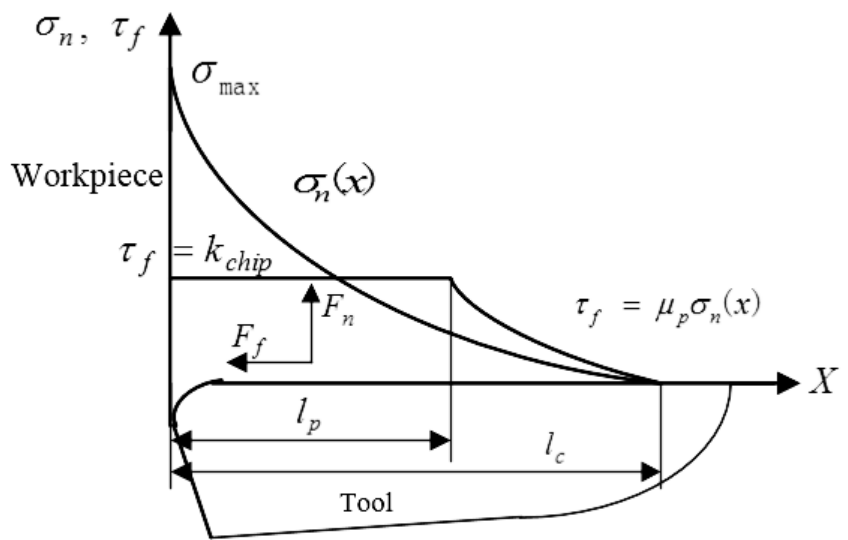

Figure 7. Frictional schematic between tool and workpiece. 


\subsection{Damage Model}

In this paper, the Johnson-Cook damage criterion [40] was employed. The criterion is as follows:

$$
\dot{\varepsilon}_{f}=\left[D_{1}+D_{2} \exp \left(D_{3} \frac{p}{q}\right)\right]\left[1+D_{4} \ln \left(\frac{\dot{\varepsilon}}{\dot{\varepsilon}_{0}}\right)\right]\left(1+D_{5}\right)
$$

In Equation (11), $D_{1}-D_{5}$ are the failure parameters, $p$ is the hydrostatic pressure, $q$ is the Mises stress, $\dot{\varepsilon}_{0}$ is the reference strain rate, and $\dot{\varepsilon}$ is the failure strain. The constants of Johnson-Cook fracture criterion D1-D5 are $0.62,0.14,-0.25,0.011$, and 2.3 , respectively.

\section{Results of Cutting Simulation}

In metal cutting process, the chip will show a variety of different shapes due to the differences of workpiece material, tool geometry, cutting parameters, and other processing conditions. Figure 8 is the cutting process of gray cast iron obtained by the simulation. When the tool made contact with the workpiece, the stress of the shear band increased, and the crack occurred with the feeding of the tool, as shown in Figure 8a,b. As the crack grows rapidly, a block of chips is formed as shown in Figure 8c. When the cutting process is in a steady state, a lot of segmented chips formed and splashed out as shown in Figure 8d,e. The cutting simulation of cast iron confirmed that the chip is segmented because cast iron is a brittle material.

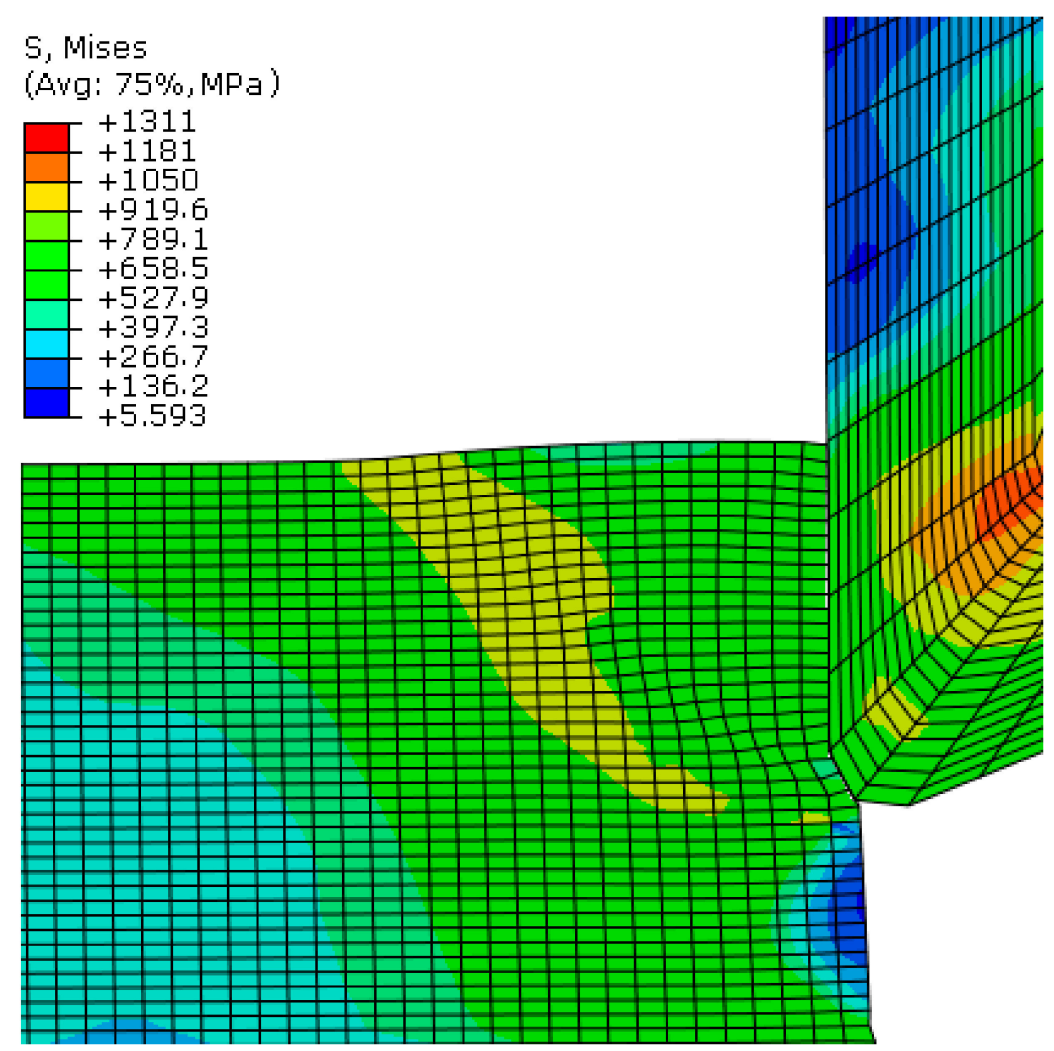

(a) The tool made contact with the workpiece.

Figure 8. Cont. 


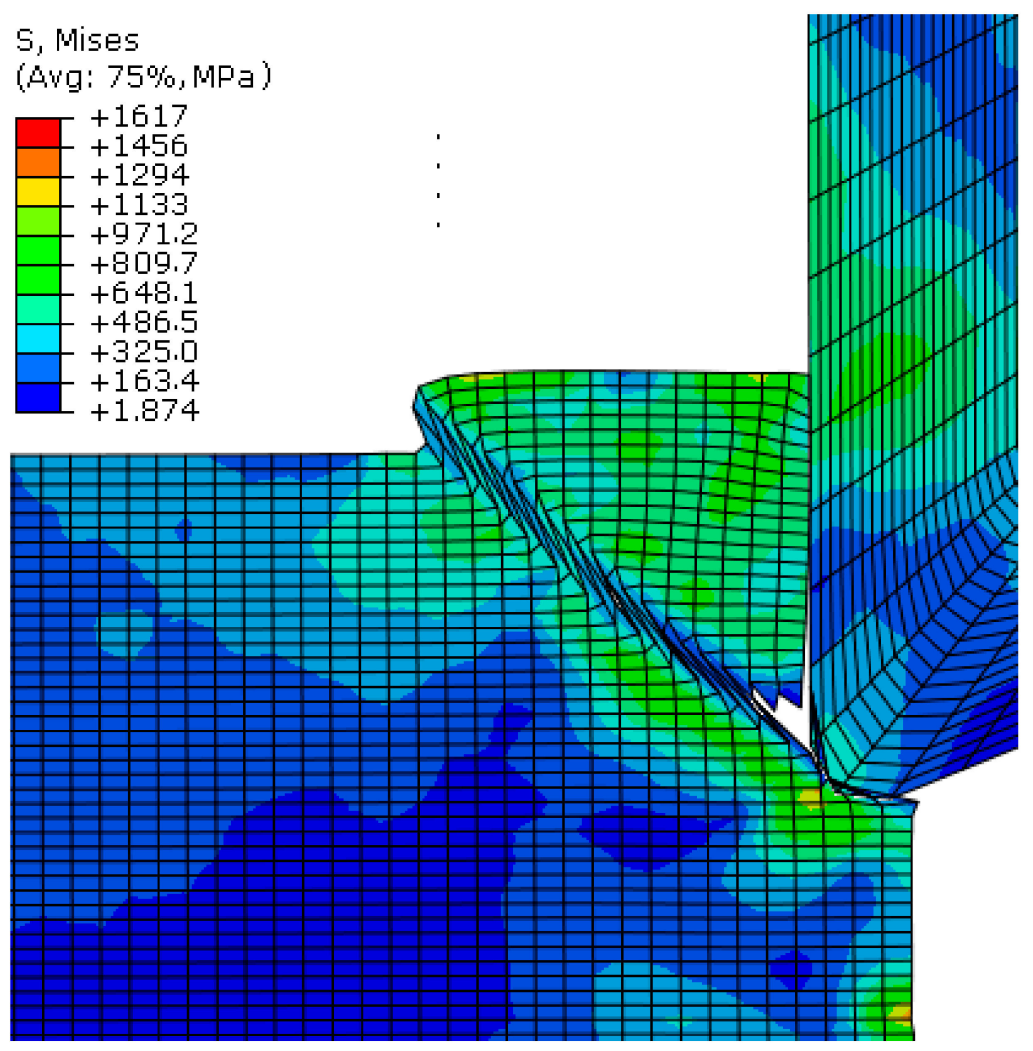

(b) The crack occurred.

\section{S, Mises}

(Avg: 75\%, MPa)

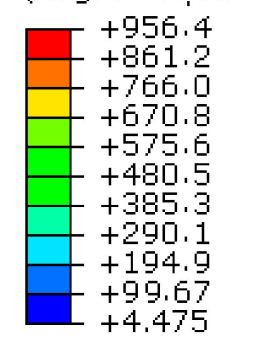

.

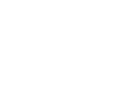




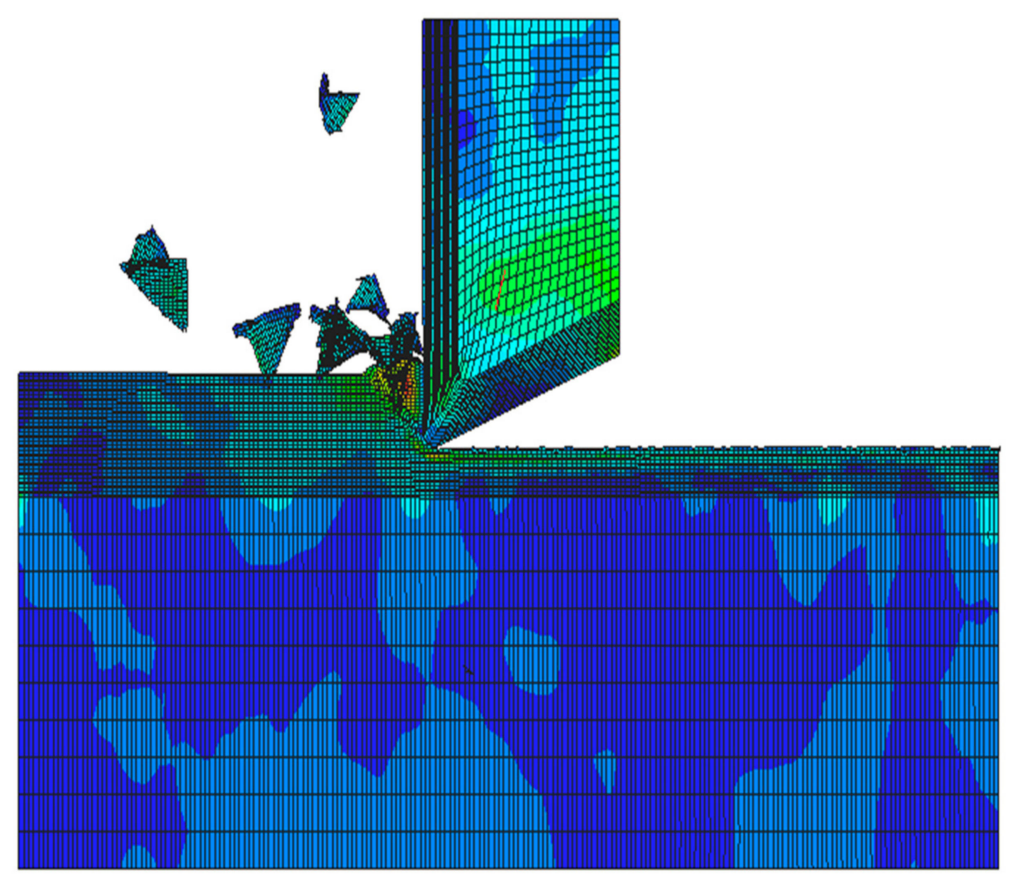

(d) The cutting entered the steady state.
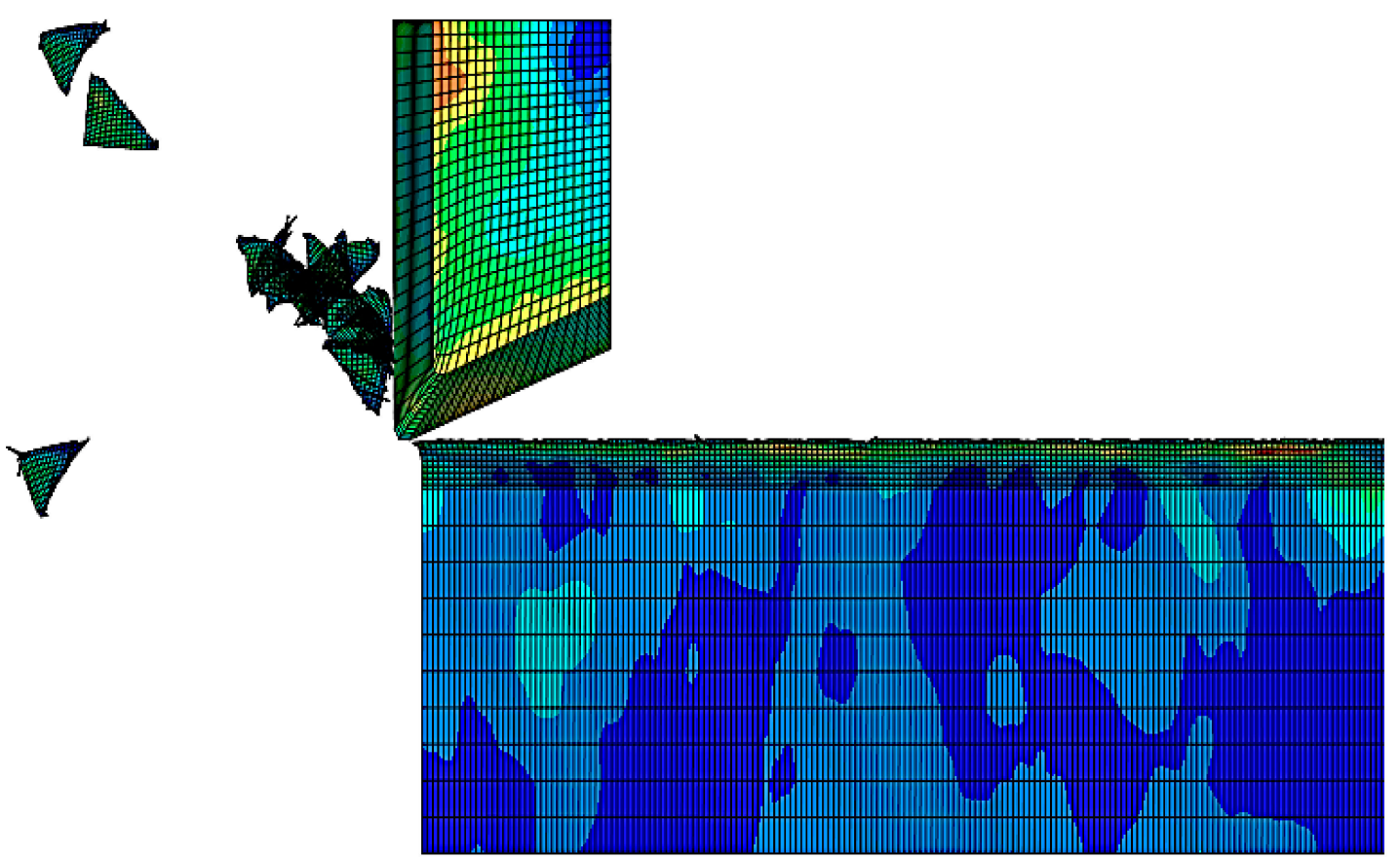

(e) The state when the cutting is completed.

Figure 8. Stress and chip formation of cast iron.

The energy consumed in the cutting process is mainly converted into cutting heat, which will cause the temperature of the tool and workpiece to rise. Cutting temperature has a direct impact on tool wear and life. Cutting heat can also change the mechanical properties and affect the generation and disappearance of chip nodules, which directly affects the cutting accuracy and cutting quality of the workpiece. Therefore, understanding the generation of cutting heat and the changing law of cutting temperature is important when studying the metal cutting process. Figure 9 shows the temperature distribution in the cutting process of gray cast iron under different states. The position of the highest 
temperature in the workpiece is located in the shear zone in contact with the tool tip, and the highest temperature area on the tool is also at the tool tip. Because the chip of gray cast iron is segmented, the contact length between the tool rake surface and chip is very short. The cutting force and cutting heat are concentrated near the cutting edge, which makes it easy to cause the tool to wear and damage.

Due to the difference of workpiece material, tool geometry and cutting parameters, and other processing conditions in the metal cutting, different deformation degree of materials will produce various forms of chips. The research of chip formation in the metal machining is very significant for the cutting mechanism of metals. Figure 10 is the photo of chip state obtained in the turning process of gray cast iron. The image demonstrates that the chip of cast iron is segmented.

Cutting force is the force that causes the material to deform and form chips when the cutter cuts into the workpiece. According to the main motion direction, cutting depth direction and feed direction, cutting force can be decomposed into three mutually perpendicular three components, the direction of cutting speed, the direction of cutting depth and the direction of feed speed. The primary cutting force is the component force in the direction of the cutting speed. Figure 11 is the comparison of the primary cutting force between cutting simulation and experiment of gray cast iron. It can be seen that the cutting force fluctuated wildly with the formation of the segmented chips. The fluctuation of the cutting force will decrease the surface quality and tool wear fast.

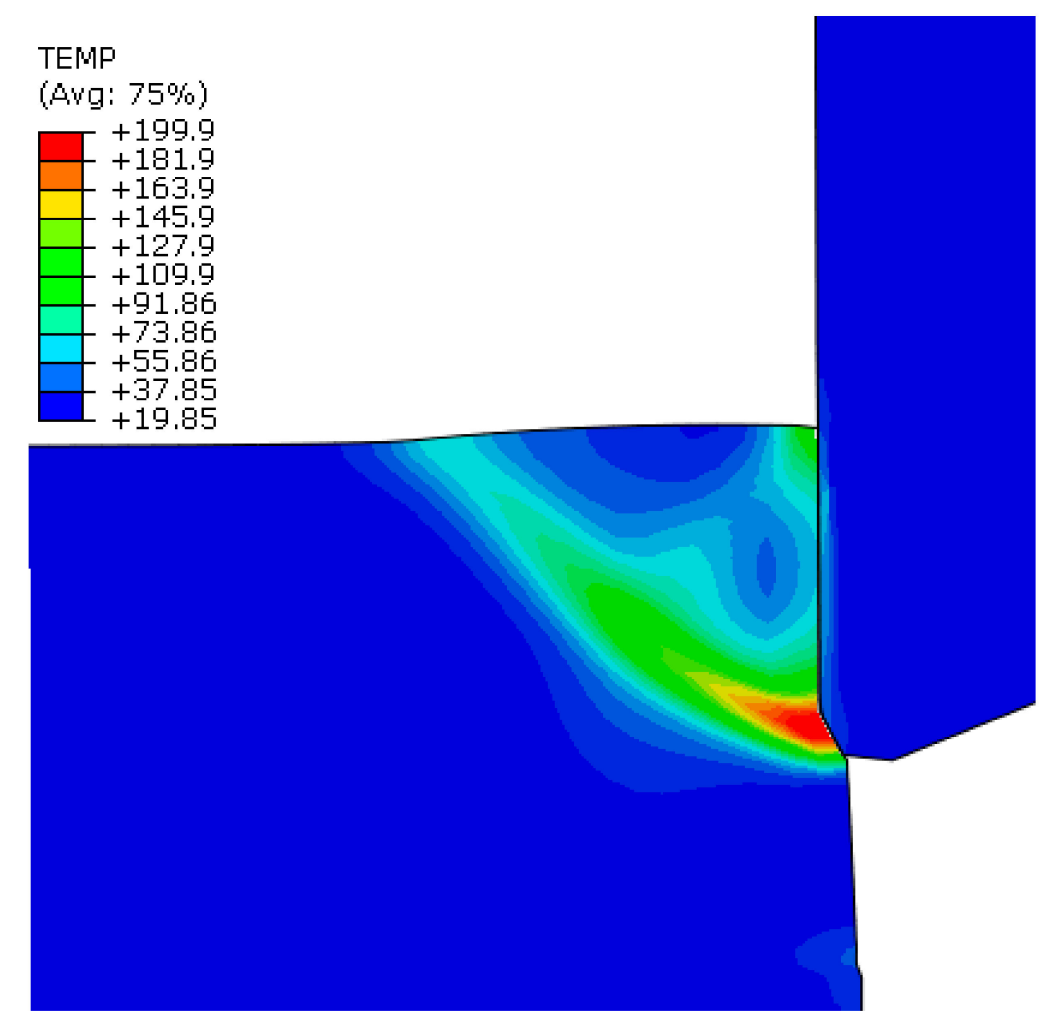

(a) When the tool begins to cut.

Figure 9. Cont. 


\section{TEMP}

(Avg: $75 \%$ )
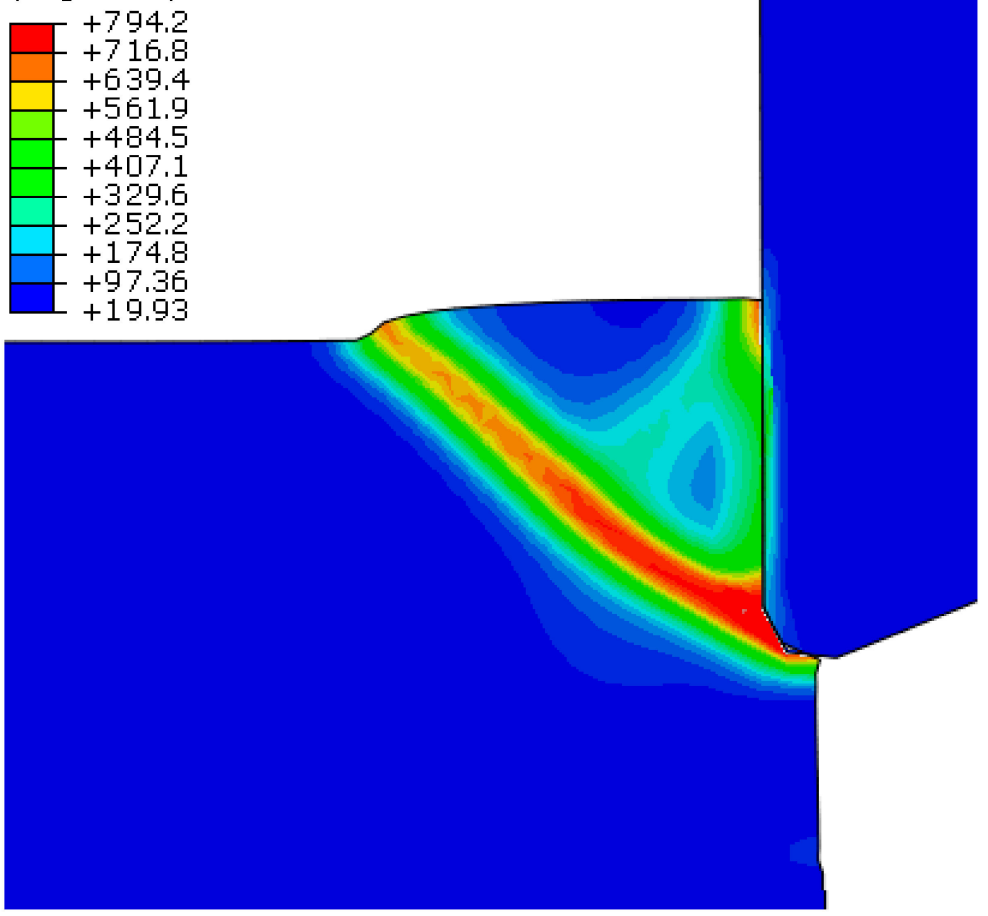

(b) The crack begins to occur.
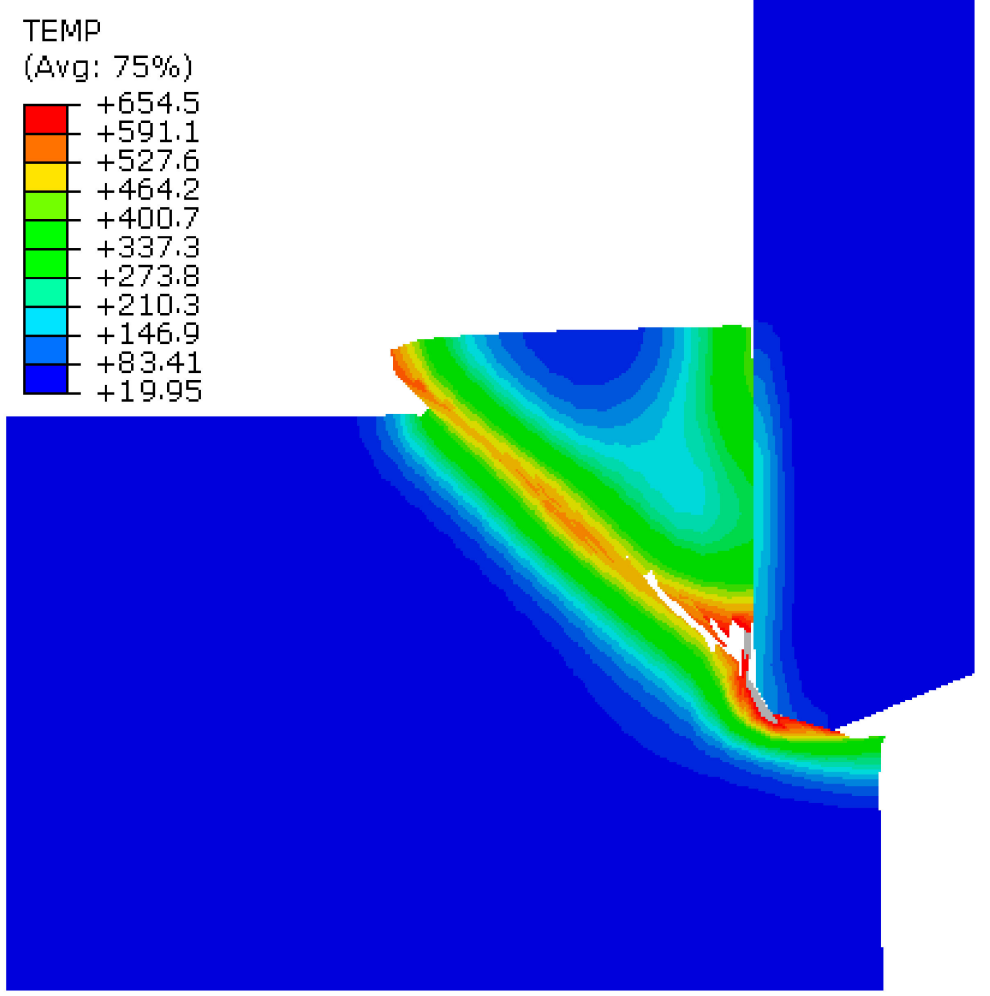

(c) A block of chip formed. 


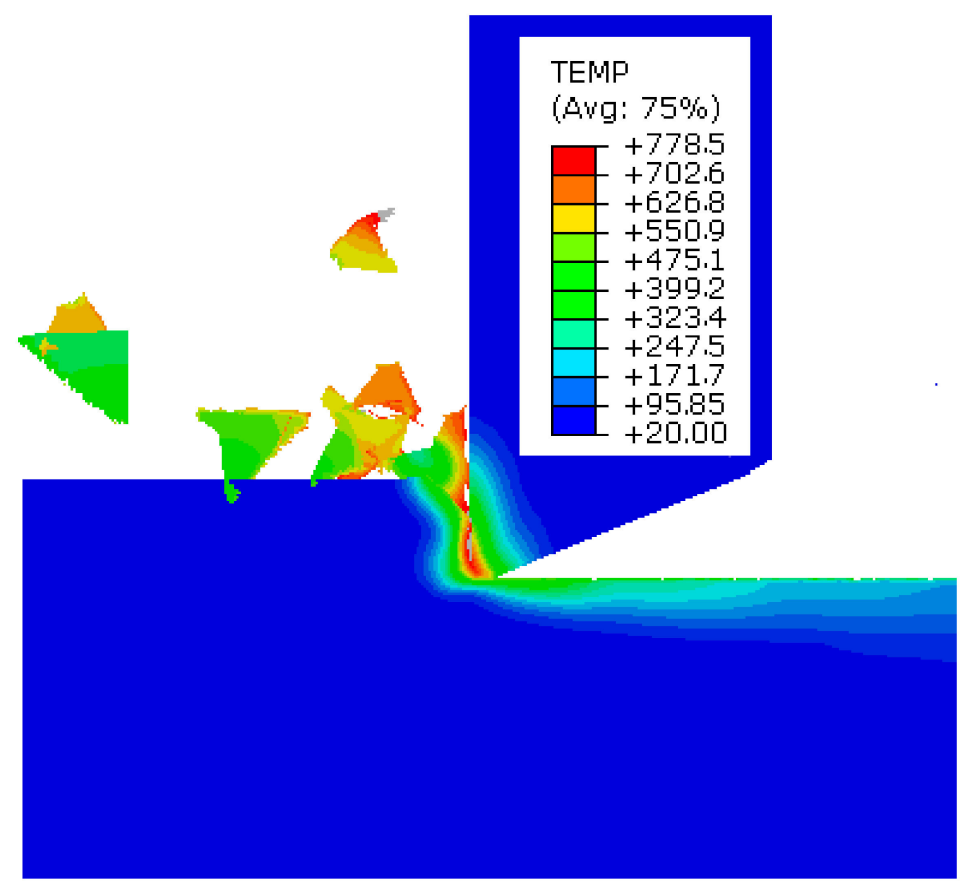

(d) The cutting stabilizes.

Figure 9. Temperature distribution in the cutting process of cast iron.

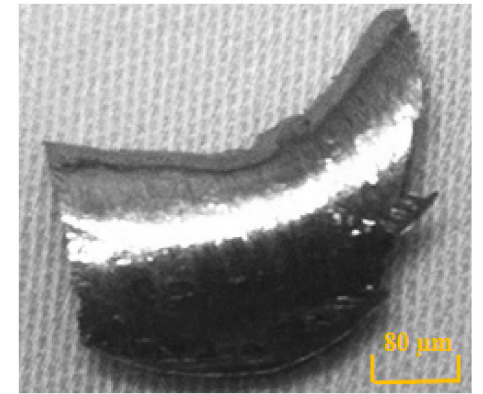

(a) Morphology of chip surface contact with tool.

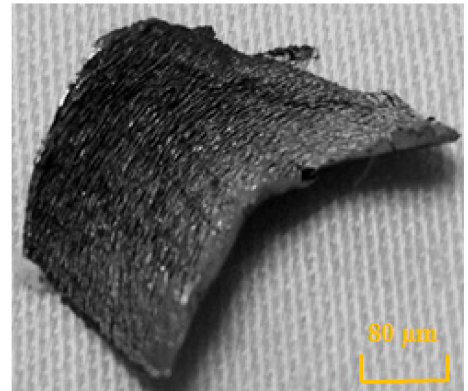

(b) Morphology of chip surface no contact with tool.

Figure 10. Segmented chips of gray cast iron.

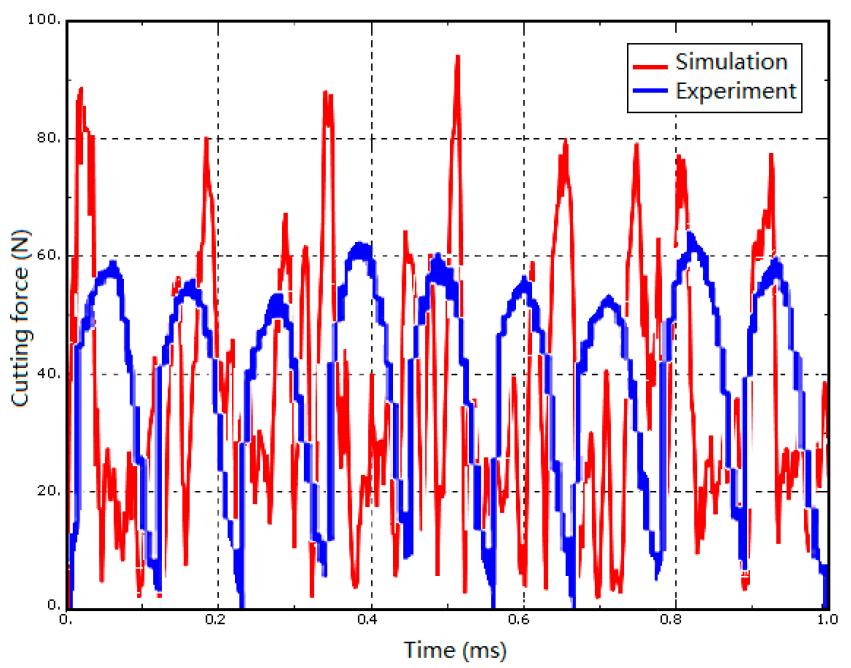

Figure 11. Comparison of primary cutting force between simulation and test. 


\section{Conclusions}

Metal cutting is a process that involves a high temperature, high strain, and high strain rate. The finite element method has been used to analyze the various cutting phenomena and the material constitutive model is needed in the cutting simulation. Aiming at the cutting of gray cast iron, to reflect the thermomechanical behavior in the cutting, a lot of SHPB compressive experiments at high temperature and strain rate were carried to investigate the dynamic mechanical properties of gray cast iron. The stress-strain relationship of gray cast iron under the different temperatures and strain rates were obtained through SHPB tests. At the same time, to reveal the cutting mechanism of gray cast iron, the Johnson-Cook constitutive model was established based on the SHPB tests. To ensure the accuracy of the simulation, the SHPB tests covered a series of strain rates and temperatures. An orthogonal cutting model with the JC material model was developed using the software ABAQUAS to simulate the cutting of gray cast iron. The chip formation, stress, cutting temperature, and cutting force have been achieved through the simulation. The results of the simulation and experiment show a good agreement with respect to chip formation and cutting force. The results of the simulation have been verified by the experiment.

Author Contributions: W.S. proposed the research method, and L.T. conducted the experiments and related research work. All authors have read and agreed to the published version of the manuscript.

Funding: This research received no external funding.

Conflicts of Interest: The authors declare no conflict of interest.

\section{References}

1. Fallböhmer, P.; Rodríguez, C.A.; Özel, T.; Altan, T. High-speed machining of cast iron and alloy steels for die and mold manufacturing. J. Mater. Process. Technol. 2000, 98, 104-115. [CrossRef]

2. Kato, H.; Shintani, K.; Sumiya, H. Cutting performance of a binder-less sintered cubic boron nitride tool in the high-speed milling of gray cast iron. J. Mater. Process. Technol. 2002, 127, 217-221. [CrossRef]

3. Yang, Y.; Li, J.F. Study on mechanism of chip formation during high-speed milling of alloy cast iron. Int. J. Adv. Manuf. Technol. 2010, 46, 43-50. [CrossRef]

4. Oliveira, A.J.D.; Boing, D.; Schroeter, R.B. Effect of PCBN tool grade and cutting type on hard turning of high-chromium white cast iron. Int. J. Adv. Manuf. Technol. 2016, 82, 797-807. [CrossRef]

5. De Sales, A.M., Jr; Sales, W.F.; Santos, S.C.; Machado, A.R. Performance of single $\mathrm{Si}_{3} \mathrm{~N}_{4}$, and mixed $\mathrm{Si}_{3} \mathrm{~N}_{4}+\mathrm{PCBN}$ wiper cutting tools applied to high speed face milling of cast iron. Int. J. Mach. Tools Manuf. 2005, 45, 335-344.

6. Martinez, I.; Tanaka, R.; Yamane, Y.; Sekiya, K.; Yamada, K.; Ishihara, T.; Furuya, S. Wear characteristics of coated carbide tools in the face milling of ductile cast iron. Key Eng. Mater. 2017, 749, 178-184. [CrossRef]

7. Chen, L.; Stahl, J.E.; Zhao, W.; Zhou, J. Assessment on abrasiveness of high chromium cast iron material on the wear performance of PCBN cutting tools in dry machining. J. Mater. Process. Technol. 2017, 255, 110-120. [CrossRef]

8. Luan, X.; Zhang, S.; Cai, G. Optimal Cutting Parameters to Reduce Power Consumption in Face Milling of a Cast Iron Alloy for Environmental Sustainability. In Proceedings of the International Conference on Sustainable Design and Manufacturing, Heraklion, Greece, 4-6 April 2016; Volume 52, pp. 135-148.

9. Xie, J.Q.; Bayoumi, A.E.; Zbib, H.M. FEA modeling and simulation of shear localized chip formation in metal cutting. Int. J. Mach. Tools Manuf. 1998, 38, 1067-1087. [CrossRef]

10. Shih, A.J. Finite element analysis of the rake angle effects in orthogonal metal cutting. Int. J. Mech. Sci. 1995, 38, 1-17. [CrossRef]

11. Wu, H.B.; Zhang, S.J. Effects of cutting conditions on the milling process of titanium alloy Ti6Al4V. Int. J. Adv. Manuf. Technol. 2015, 77, 2235-2240. [CrossRef]

12. Matsumura, T.; Usui, E. Simulation of cutting process in peripheral milling by predictive cutting force model based on minimum cutting energy. Int. J. Mach. Tools Manuf. 2010, 50, 467-473. [CrossRef]

13. Maurel-Pantel, A.; Fontaine, M.; Thibaud, S.; Gelin, J.C. 3D FEM simulations of shoulder milling operations on a 304L stainless steel. Simul. Model. Pract. Theory 2012, 22, 13-27. [CrossRef] 
14. Ji, C.; Li, Y.; Qin, X.; Zhao, Q.; Sun, D. 3D FEM simulation of helical milling hole process for titanium alloy Ti-6Al-4V. Int. J. Adv. Manuf. Technol. 2015, 81, 1733-1742. [CrossRef]

15. Mir, A.; Luo, X.; Siddiq, A. Smooth particle hydrodynamics study of surface defect machining for diamond turning of silicon. Int. J. Adv. Manuf. Technol. 2017, 88, 2461-2476. [CrossRef]

16. Wu, H.B.; Guo, L. Machinability of titanium alloy TC21 under orthogonal turning process. Mater. Manuf. Process. 2014, 29, 1441-1445. [CrossRef]

17. Kilic, Z.M.; Altintas, Y. Generalized modelling of cutting tool geometries for unified process simulation. Int. J. Mach. Tools Manuf. 2016, 104, 14-25. [CrossRef]

18. Jafarian, F.; Ciaran, M.I.; Umbrello, D.; Arrazola, P.L.; Filice, L. Finite element simulation of machining Inconel 718 alloy including microstructure changes. Int. J. Mech. Sci. 2014, 88, 110-121. [CrossRef]

19. Komvopoulos, K.; Erpenbeck, S.A. Finite element modeling of orthogonal metal cutting. J. Eng. Ind. 1991, 113, 253. [CrossRef]

20. Ceretti, E.; Lucchi, M.; Altan, T. FEM simulation of orthogonal cutting: Serrated chip formation. J. Mater. Process. Technol. 1999, 95, 17-26. [CrossRef]

21. Özel, T.; Altan, T. Process simulation using finite element method-prediction of cutting forces, tool stresses and temperatures in high-speed flat end milling. Int. J. Mach. Tools Manuf. 2000, 40, 713-738. [CrossRef]

22. Xiong, R.; Wu, H. Study on cutting mechanism of Ti6Al4V in ultra-precision machining. Int. J. Adv. Manuf. Technol. 2016, 86, 1-7.

23. Paturi, U.M.R.; Narala, S.K.R.; Pundir, R.S. Constitutive flow stress formulation, model validation and FE cutting simulation for AA7075-T6 aluminum alloy. Mater. Sci. Eng. A 2014, 605, 176-185. [CrossRef]

24. Boldyrev, I.S.; Shchurov, I.A.; Nikonov, A.V. Numerical simulation of the aluminum 6061-T6 cutting and the effect of the constitutive material model and failure criteria on cutting forces' prediction. Procedia Eng. 2016, 150, 866-870. [CrossRef]

25. Umbrello, D. Finite element simulation of conventional and high speed machining of Ti6Al4V alloy. J. Mater. Process. Technol. 2007, 196, 79-87. [CrossRef]

26. Pantalé, O.; Bacaria, J.-L.; Dalverny, O.; Rakotomalala, R.; Caperaa, S. 2D and 3D numerical models of metal cutting with damage effects. Comput. Methods Appl. Mech. Eng. 2004, 193, 4383-4399. [CrossRef]

27. Johnson, R.; Cook, W.K. A constitutive model and data for metals subjected to large strains high strain rates and high temperatures. In Proceedings of the 7th International Symposium on Balistics, The Hague, The Netherlands, 19-21 April 1983; pp. 541-547.

28. Daoud, M.; Chatelain, J.F.; Bouzid, A. Effect of rake angle on Johnson-Cook material constants and their impact on cutting process parameters of Al2024-T3 alloy machining simulation. Int. J. Adv. Manuf. Technol. 2015, 81, 1987-1997. [CrossRef]

29. Shrot, A.; Bäker, M. Is it possible to identify Johnson-Cook law parameters from machining simulations? Int. J. Mater. Form. 2010, 3, 443-446. [CrossRef]

30. Wu, H.B.; To, S. Serrated chip formation and their adiabatic analysis by using the constitutive model of titanium alloy in high speed cutting. J. Alloy. Compd. 2015, 629, 368-373. [CrossRef]

31. Wang, X.; Huang, C.; Zou, B.; Liu, H.; Zhu, H.; Wang, J. Dynamic behavior and a modified Johnson-Cook constitutive model of Inconel 718 at high strain rate and elevated temperature. Mater. Sci. Eng. A 2013, 580, 385-390. [CrossRef]

32. Seo, S.; Min, O.; Yang, H. Constitutive equation for Ti-6Al-4V at high temperatures measured using the SHPB technique. Int. J. Impact Eng. 2005, 31, 735-754. [CrossRef]

33. Zhong, W.Z.; Mbarek, I.A.; Rusinek, A.; Bernier, R.; Jankowiak, T. Development of an experimental set-up for dynamic force measurements during impact and perforation, coupling to numerical simulations. Int. J. Impact Eng. 2016, 91, 102-115. [CrossRef]

34. Jaspers, S.P.F.C.; Dautzenberg, J.H. Material behaviour in conditions similar to metal cutting: flow stress in the primary shear zone. J. Mater. Process. Technol. 2002, 122, 322-330. [CrossRef]

35. Dabboussi, W.; Nemes, J.A. Modeling of ductile fracture using the dynamic punch test. Int. J. Mech. Sci. 2005, 47, 1282-1299. [CrossRef]

36. Zhou, T.; Wu, J.; Che, J.; Wang, Y.; Wang, X. Dynamic shear characteristics of titanium alloy Ti-6Al-4V at large strain rates by the split hopkinson pressure bar test. Int. J. Impact Eng. 2017, 109, 167-177. [CrossRef]

37. Church, P.; Cornish, R.; Cullis, I.; Gould, P.; Lewtas, I. Using the split Hopkinson pressure bar to validate material models. Philos. Trans. R. Soc. A Math. Phys. Eng. Sci. 2014, 372, 20130294. [CrossRef] [PubMed] 
38. Fowles, R.; Williams, R.F. Plane stress wave propagation in solids. J. Appl. Phys. 1970, 41, 360-363. [CrossRef]

39. Zorev, N.N. Inter-relationship between shear processes occurring along tool face and shear plane in metal cutting. Int. Res. Prod. Eng. 1963, 5, 42-49.

40. Johnson, G.R.; Cook, W.H. Fracture characteristics of three metals subjected to various strains, strain rates, temperatures and pressures. Eng. Fract. Mech. 1985, 21, 31-48. [CrossRef]

(C) 2019 by the authors. Licensee MDPI, Basel, Switzerland. This article is an open access article distributed under the terms and conditions of the Creative Commons Attribution (CC BY) license (http://creativecommons.org/licenses/by/4.0/). 